\title{
Gene therapy for hemoglobin disorders - a mini-review
}

Parul Rai ${ }^{1}$ and Punam Malik ${ }^{1,2 *}$

'Cincinnati Children's Hospital Medical Center, Cincinnati, OH, USA

${ }^{2}$ Department of Pediatrics, University of Cincinnati College of Medicine, Cincinnati, OH 45229, USA

\section{Article Info}

\section{Article Notes}

Received: August 01, 2016

Accepted: August 31, 2016

\section{*Correspondence}

Punam Malik, MD, Cincinnati Children's Hospital Medical

Center, Division of Experimental Hematology and Cancer

Biology and the Division of Hematology, Cancer and Blood

Disease Institute, Cincinnati Children's Hospital Medical Center

3333 Burnet Ave, Cincinnati OH 45229, USA

E-mail: punam.malik@cchmc.org

(c) 2016 Punam Malik. This article is distributed under the terms of the Creative Commons Attribution 4.0 International License.

\section{Keywords}

Gene

Hemoglobinopathies

Sickle cell anemia

Thalassemia

Hemoglobin

Therapy

Review

Disorders

\section{ABSTRACT}

Gene therapy by either gene insertion or editing is an exciting curative therapeutic option for monogenic hemoglobin disorders like sickle cell disease and $\beta$-thalassemia. The safety and efficacy of gene transfer techniques has markedly improved with the use of lentivirus vectors. The clinical translation of this technology has met with good success, although key limitations include number of engraftable transduced hematopoietic stem cells and adequate transgene expression that results in complete correction of $\beta 0$ thalassemia major. This highlights the need to identify and address factors that might be contributing to the in-vivo survival of the transduced hematopoietic stem cells or find means to improve expression from current vectors. In this review, we briefly discuss the gene therapy strategies specific to hemoglobinopathies, the success of the preclinical models and the current status of gene therapy clinical trials.

\section{Introduction}

Sickle cell disease (SCD) and $\beta$-thalassemia are autosomal recessive disorders that result in qualitative and quantitative defects in $\beta$-globin protein production; and are highly prevalent worldwide, with approximately $7 \%$ of the global population estimated to be carriers of hemoglobin gene-variants, and over 330,000 affected infants born annually with SCD alone ${ }^{1}$. Despite improved medical supportive therapies, significant long-term mortality and morbidity associated with hemoglobinopathies remains ${ }^{2,3}$. Hematopoietic stem cell transplant (HSCT) provides the only definitive cure, with a disease free survival exceeding $80 \%$ with HLA-matched sibling donor transplants ${ }^{4,5}$. Improvements in management of graft versus host disease (GVHD) and better means of inducing graft tolerance have encouraged the use of an extended donor pool comprising of unrelated donors and umbilical cord blood as the hematopoietic stem cell (HSC) source for patients lacking a matched sibling donor ${ }^{6}$. However, matched-unrelated HSCT for thalassemia have an overall survival of $65 \%$ in the high risk patients 7 . In addition, a $5-10 \%$ mortality from transplant-conditioning, GVHD and graft failure continues to limit the acceptability of this treatment modality ${ }^{8}$.

Gene therapy, using genetically-modified autologous HSCs is an attractive alternative to allogeneic HSCT, and specifically unrelateddonor HSCT, since it eliminates the need for a matched donor and the risk of GVHD/graft rejection. Successful gene therapy for monogenic immune disorders like chronic granulomatous disease and severe combined immunodeficiency ${ }^{9-13}$ has encouraged development of this technology for hemoglobinopathies. Whereas in immunodeficiency disorders, the genetically modified hematopoietic progenitors and $\mathrm{T}$ cells have a selective survival advantage and a tremendous expansion 
potential, respectively, requiring a minimal (0.1-1\%) gene corrected HSC engraftment for sustained correction of lymphoid dysfunction ${ }^{14}$; in hemoglobinopathies, no such survival advantage of genetically modified HSCs/ progenitors is present, and selective advantage is limited to the terminal erythroid cells ${ }^{15}$. Post-transplant followup studies ${ }^{16}$ and murine models ${ }^{17,18}$ show that a $20 \%$ donor chimerism is essential for improving the clinical manifestations in SCD and thalassemia, a level requiring substantial pre-transplant chemotherapy conditioning. Furthermore, in order for globin gene transfer to affect a cure, high level erythroid lineage specific expression is necessary.

Despite these hurdles, improved vector potency and safety have significantly advanced the field, resulting in cures in patients with Hemoglobin E- $\beta$-thalassemia and considerable disease amelioration in some patients with $\beta 0$ thalassemia and SCD. The lessons learnt from these early gene therapy trials suggest that engraftment of sufficient transduced HSC, or their in-vivo selection could play a crucial role to extend the curative capacity of gene therapy.

\section{Vector development for hemoglobin disorders}

Correction of hemoglobin disorders by vector-mediated gene transfer requires utilization of a safe delivery vehicle/ vector to efficiently transfer the complex $\beta$-transgene cassette to HSCs and result in sustained high expression of the transferred globin gene. The vectors commonly used have been bioengineered from different retroviruses, mainly murine Moloney leukemia virus (retrovirus vectors; RV), HIV-1 (lentivirus vectors; LV) and foamy virus, after removing the genetic elements responsible for their pathogenicity and virulence, and adding the $\beta$-globin gene and its locus control region (LCR) elements. Of these, LV have been most successful at correcting hemoglobinopathy animal models, and have resulted in their clinical translation.

The $\beta$-globin LCR is a cis-regulatory element composed of five DNAase-1 hypersensitivity sites, four of which are formed in the erythroid cells ${ }^{19}$. When linked to the globin genes LCR leads to position-independent, erythroid lineage-specific enhancement of globin gene expression. The enhancer activity of LCR resides in three of its hypersensitivity sites HS 2, 3 and 4, which contain an array of binding sites for ubiquitous and erythroid specific transcription factors ${ }^{20}$. An intact LCR (5'HS 1-5) is involved in maintaining an open chromatin conformation that is needed for position independent expression of the globin genes. The LCR also results in developmental regulation of globin expression and interacts with the $\varepsilon, \gamma$ and $\beta$ globin gene promoters in the embryonic, fetal and adult stage, respectively ${ }^{21}$

\section{Gamma-retrovirus (RV) vectors}

Initial studies looking at RV-mediated human $\beta$-globin gene transfer without inclusion of the LCR elements, showed variable and low levels of gene expression $(<1 \%$ of endogenous $\beta$-globin expression $)^{22}$. Following this study, nearly one decade of efforts to develop RV for expressing sufficient globin gene expression were futile ${ }^{23,24}$.

RVs utilizing the enhancer/promoter sequences of the LTR (long terminal repeat) to drive transgene expression of genes other than globin genes, were the first ones to be used in clinical trials. Despite their initial clinical success in gene therapy of immune-deficiencies, concerns about their safety emerged following reports of vector-mediated insertional mutagenesis $^{9-12}$. Integration site analysis revealed that the RVs have a tendency to integrate near cellular promoters, retroviral common integration sites (CIS) and cancer genes, independent of the vector design, and enhance their expression via the LTR promoter/enhancer. The RV vector insertions increase immortalization of primary hematopoietic progenitor cells ${ }^{25}$. While the RV LTR is a strong enhancer and upregulates transgene expression to very high levels compared to relatively weaker enhancers from the HIV LTR and cytomegalovirus ${ }^{26}$, it also simultaneously activates cellular proto- oncogenes flanking insertion sites ${ }^{27}$. Additionally, methylation of the LTR can lead to inactivation of the integrated transgene promoter and prevent long-term transgene expression ${ }^{28}$. The construction of a self-inactivating [SIN] vector design deletes the LTR promoter/enhancer and allows the transgene expression to be driven by internal cellular promoters, reduce LTR enhancer-mediated genotoxicity ${ }^{27}$ and its methylation-induced inactivation ${ }^{29}$. Inclusion of the chicken $\beta$-globin hypersensitive site- 4 (cHS4) insulator element to the SIN vector further improved its safety by reducing position dependent variablility in gene expression $^{30}$. However the inability of RV to transduce non-diving cells, along with vector instability seen with incorporation of large LCR sequences greatly limited their use in gene therapy for hemoglobin disorders ${ }^{31}$.

\section{Lentivirus vectors}

The interest in LV was generated with the increasing knowledge of the basic structure and properties of HIV-1 virus. HIV-1 can efficiently translocate the intact nuclear membrane and thus, has the ability to transduce nondividing/quiescent cells and can carry larger expression cassettes. These features enabled the HIV-1 based LVs to be developed for hemoglobinopathies, and efficiently transfer the $\beta$-transgene/LCR to HSCs for sustained correction of the hemoglobin defect. The major safety concerns with the use of LVs initially were risk of generating a 
replication-competent lentivirus (RCL) and insertional mutagenesis. The former risk has been eliminated by removal of HIV regulatory and accessory genes from vector plasmids and constructing the vector with 3-4 separate packaging plasmids, with minimal overlapping sequences between and within them ${ }^{31}$. The preference for intragenic integration of LV vectors, coupled with the SIN design considerably reduces their genotoxicity potential; Indeed, recent LV clinical trials with a follow up of nearly 10 years have shown no genotoxicity resulting from $L V$ vectors, even though, preclinical studies have reported vector integration in known oncogenes (MLL, NUP214) ${ }^{32}$ and suggested that transcriptionally active enhancers like the LCR can lead to gene dysregulation, independent of the vector type (RV or LV) or design (LTR-based or SIN) ${ }^{26,33}$.

Our group explored the genotoxicity potential of LCR enhancer elements and showed that the LCR-containing LVs have approximately 200-fold lower immortalization potential than RVs. Though gene dysregulation was seen in the vicinity of the integrated vector, no protooncogene upregulation was noted ${ }^{34}$. Use of cHS4 insulators decreased the transforming potential further, along with decreasing position dependent variable gene expression and methylation-associated silencing ${ }^{35}$.

\section{Preclinical studies}

\section{Gene Therapy for $\beta$-Thalassemia}

LV-mediated human $\beta$-gene transfer was shown to rescue mouse models of $\beta$-thalassemia intermedia and $\beta$-thalassemia major. May and colleagues demonstrated the use of a LV vector carrying the human $\beta$-globin gene fragment and $\beta$-globin LCR spanning the HS2, HS3, and HS4 regions to correct thalassemia intermedia in mice with increase in hemoglobin levels by $3-4 \mathrm{~g} / \mathrm{dl}^{36}$. The same group developed an adult $\beta 0$-thalassemia major mouse model using mice engrafted with beta-globin-null $\mathrm{Hbb}(\mathrm{th} 3 / \mathrm{th} 3)$ fetal liver cells and rescued their severe phenotype using the same vector with an average vector copy number (VCN) of 1.0- $2.4^{18}$. Imren and coworkers thereafter showed correction of $\beta$-thalassemia mice using a vector carrying the $\beta$ T 87Q gene, where a point mutation in the $\beta$-globin gene also confers it with anti-sickling properties. However, multiple copies were required for adequate correction of the mouse thalassemia phenotype $\mathrm{e}^{32}$. Our group showed complete correction of the human $\beta 0$ thalassemia phenotype in vitro and in a xenograft model with approximately 2 vector copies/cell ${ }^{37}$. Miccio and colleagues used a $\mathrm{LV}$ vector carrying the $\beta$-globin gene linked to a minimized LCR HS2/HS3. They showed that a frequency of $30-50 \%$ of transduced hematopoietic cells harboring an average VCN of 1 was sufficient to fully correct the thalassemia phenotype in th $3 /+$ mice $^{15}$. In addition they also demonstrated that the genetically corrected erythroblasts had an in vivo survival advantage, thus encouraging the need to explore the utility of reduced intensity transplant regimens for clinical gene therapy trials.

\section{Gene Therapy for SCD}

The efficacy of LV-mediated transfer of $\gamma$-globin gene/mutated $\beta$-globin genes ( $\beta$ T87Q and $\beta A S 3$ ) for correcting SCD was explored using transgenic and humanized xenograft sickle cell murine models. Pawliuk and colleagues showed improvement in hematological parameters, splenomegaly and hyposthenuria in BERK and SAD mice using the $\beta$ T87Q $\mathrm{LV}^{38}$. Levasseur on the other hand used a $\beta A S 3$ (a human $\beta$-globin gene with 3 anti-sickling mutations) in a LV to successfully transduce murine HSC without cytokine stimulation ${ }^{39}$. Romero et al used the same $\beta A S 3$ LV to successfully transduce bone marrow CD34 progenitor cells from patients with SCD, and produce sufficient levels of anti-sickling hemoglobin ${ }^{40}$. Persons et $\mathrm{al}^{41}$, and Pestina et $\mathrm{al}^{42}$ showed improvement in SCD phenotype by increasing the expression of fetal hemoglobin $(\mathrm{HbF})$ using $\gamma$-globin LV. Our group showed an $18-20 \%$ engraftment of HSCs containing $\gamma$-globin gene-LV, following a non-myeloablative conditioning regimen. This donor chimerism was sufficient to result in approximately $60 \%$ circulating $\mathrm{RBC}$ containing $\mathrm{HbF}$ (F cells) with an improvement in the SCD manifestations ${ }^{43}$.

\section{Clinical trials}

The success in preclinical models, supported by safety studies on LV vectors led to the design of clinical gene therapy trials. Cavazzana-Calvo et al. enrolled a hemoglobin $E / \beta(\beta E / \beta 0)$-thalassemia major patient in 2007 who received genetically modified autologous HSCs expressing $\beta$ T87Q-globin following myeloablative busulfan conditioning. This subject became transfusion independent 1-2 years later ${ }^{44}$ with a hemoglobin maintained at 9-10 $\mathrm{gm} / \mathrm{dl}$. This therapeutic benefit was initially due to a clonal expansion observed following vector insertion in the HMGA2 gene. However this clone has eventually subsided. The trial was subsequently extended to include 18 patients with thalassemia (transfusion-dependent $\beta E \beta 0 n=10, \beta 0 \beta 0$ $n=5, \beta$ thalassemia $n=3$ ) and 4 patients with $\operatorname{SCA}^{45-47}$. All patients with $\beta E \beta 0$-thalassemia and $\beta+$ thalassemia became transfusion independent within a year of transplant, with a median increase in hemoglobin by $4.9-\mathrm{g} / \mathrm{dl}$, while patients with $\beta 0 \beta 0$-thalassemia with a similar hemoglobin increase experienced a significant reduction in their transfusion requirement, but were not transfusion independent, since the baseline hemoglobin levels in $\beta 0 \beta 0$ thalassemia are much lower than in individuals with $\beta+/ \beta E$ thalassemia. One of four patients with SCD who received a high dose of transduced CD34 cells had remarkable improvement in their SCD phenotype. 
Two other trials are using the $\beta$-globin $\mathrm{LV}$ vectors for $\beta$-thalassemia. In the trial led by Boulad et al (NCT01639690), the preconditioning regimen had to be switched from a reduced-intensity busulfan to myeloablative doses following modest engraftment and $\beta$-globin expression with the lower dose ${ }^{48}$; the trial led by Ferrari et al (NCT02453477) is using a myeloablative regimen consisting of treosulfan and thiotepa with initial success $^{48}$. The NCT02247843 trial led by Kohn et al. for SCD is investigating the efficacy of $\beta A S 3 \mathrm{LV}$, and the trial led by our group (Malik et al.; NCT02186418) is using a $\gamma$-globin $\mathrm{LV}$ following reduced intensity conditioning. The results of these studies are eagerly awaited.

\section{Recent Advances in Genetic Manipulation Technology}

The emergence of gene editing technology, which enables precise genome manipulation, offers a new approach for treating $\beta$-hemoglobinopathies ${ }^{49}$. Site specific double strand breaks (DSB) can be induced with zinc finger nucleases, transcription activator-like effector nucleases (TALENS), meganucleases and more recently with Clustered regularly interspaced short palindromic repeats (CRISPR)/Cas9 system. CRISPR/Cas9 has revolutionized gene targeting. Unlike other nucleases which use a protein dimer for target sequence recognition and require a novel protein to be engineered for each new target site, CRISPR/Cas9 technology uses a short guide RNA (gRNA) with a 20bp sequence complementary to the DNA sequence to be targeted ${ }^{50}$. In addition targeting/ knockdown of multiple genes can be achieved by using multiple gRNAs with a common Cas9 protein ${ }^{51}$. DSB is then followed by DNA repair through one of the two major pathways: 1) Non-homologous end joining (NHEJ) with direct fusion of the nuclease cleaved ends. This repair mechanism is error-prone, leading to indels, and is cellcycle stage independent ${ }^{52}$. 2) Homologous directed repair (HDR) uses an exogenous donor template ${ }^{53}$ delivered via single-stranded oligonucleotides, plasmids, or viral vectors like integrase deficient lentivirus or adeno-associated virus $^{54}$, for gene correction with targeted insertion. For hemoglobinopathies, gene editing strategizes shown to be successful include either induction of endogenous fetal hemoglobin ${ }^{55,56}$, modification of the causal $\beta$-globin gene mutation by targeted nucleases ${ }^{57}$ or therapeutic transgene integration ${ }^{58}$, or a combined approach ${ }^{59,60}$. Inactivation of an erythroid specific enhancer of BCL11A by gene editing leads to suppression of BCL11A and up-regulation of $\gamma$-globin in erythroid lineage cells ${ }^{61,62}$.

These gene editing strategizes are being performed in CD34+ stem and progenitor cells ${ }^{63}$ or in induced pluripotent stem cells (iPSCs) capable of differentiating into any somatic cell type ${ }^{64-66}$. Patient-specific iPSCs are generated by the genetic reprogramming of their somatic cells, and provide an unlimited source of stem cells which can be genetically manipulated, differentiated along a specific tissue type and returned back to the patient. Currently, active research in differentiating iPSC towards definitive hematopoietic stem cells with long term engraftment potential is underway. In addition to their therapeutic potential, iPSCs can also be used as in-vitro disease models ${ }^{67}$. Off-target nuclease binding activity $^{68}$, efficient means of delivering the genome editing tools to target stem cell populations without loss of 'stemness', genomic variation occurring with somatic reprogramming, efficient gene targeting by homology directed repair ${ }^{69}$, and developing functional HSCs from these genetically modified $\mathrm{iPSC}^{70,71}$ are some of the challenges in the field.

\section{Conclusions and future directions}

Gene therapy for hemoglobinopathies is now a reality, with several patients cured of their $\beta 0 / \beta E$ thalassemia or with significant amelioration from $\beta 0 / \beta 0$ thalassemia and one patient with SCD, while others are showing modest transgene expression. The current curative capacity of gene transfer technology is limited by the severity of the underlying disease. The increase in hemoglobin to 8-9 gm/ $\mathrm{dl}$ seen in $\beta 0 \beta 0$ thalassemia is still not sufficient to prevent ineffective erythropoiesis, and hence these subjects are still intermittently transfused. However the overall transfusion burden in this patient population has decreased dramatically. Cohen et al showed that the success of chelation therapy in achieving a neutral or negative iron balance (assessed by liver iron concentration) had a significant correlation to the transfusion iron intake ${ }^{72}$. Thus decreasing the transfusion burden is advantageous, as it not only might affect the dose of chelation therapy used but also affects its outcome.

The challenges to efficacious clinical translation in hemoglobinopathies include the dose of engraftable transduced HSCs, the intensity of the preconditioning transplant regimen, and expression of the transgene. Invivo selection strategies can ensure expansion of the few genetically-modified engrafted HSCs. Improving vector potency will augment gene expression. Efforts to promote differentiation of iPSC technology to produce engraftable HSC can expand the HSC source, and gene editing can circumvent the need for high transgene expressing- $\mathrm{LV}$ and potential, albeit low, insertional genotoxicities of LV. New technologies that can reshape the future of gene therapy are gene editing using CRISPR/CaS9 and development of hematopoietic stem cells from iPSCs with long term repopulating potential, although much work is needed to make this a reality. With scientific advancements in stem cell biology and genetic manipulation, we envision a future where a child prenatally diagnosed with hemoglobinopathy can have his/her genetically modified cord blood stem cells transfused even before the fetal to adult hemoglobin switch, thus preventing the occurrence of any disease manifestations. 


\section{Acknowledgements}

This study is supported by the Doris Duke Foundation Innovations in Clinical Research Award to PM, and the NIHNHLBI Excellence in Hemoglobinopathy Research Award (EHRA) program (U01HL117709).

\section{References}

1. Modell B, Darlison M. Global epidemiology of haemoglobin disorders and derived service indicators. Bull World Health Organ. 2008; 86(6):480-487.

2. Rachmilewitz EA, Giardina PJ. How I treat thalassemia. Blood. 2011; 118(13):3479-3488.

3. Sharef SW, Al-Hajri M, Beshlawi I, Al-Shahrabally A, Elshinawy M, Zachariah M, et al. Optimizing Hydroxyurea use in children with sickle cell disease: low dose regimen is effective. Eur J Haematol. 2013; $90(6): 519-524$.

4. Shenoy S. Hematopoietic Stem Cell Transplantation for Sickle Cell Disease: Current Practice and Emerging Trends. Hematol-Am Soc Hemat. 2011:273-279.

5. Angelucci E. Hematopoietic stem cell transplantation in thalassemia Hematology Am Soc Hematol Educ Program. 2010; 2010:456-462.

6. Walters MC, Patience M, Leisenring W, Rogers ZR, Aquino VM, Buchanan GR, et al. Stable mixed hematopoietic chimerism after bone marrow transplantation for sickle cell anemia. Biol Blood Marrow Tr. 2001; 7(12):665-673.

7. La Nasa G, Argiolu F, Giardini C, Pession A, Fagioli F, Caocci G, et al Unrelated bone marrow transplantation of beta-thalassemia patients - the experience of the Italian Bone Marrow Transplant Group. Ann Ny Acad Sci. 2005; 1054:186-195.

8. Bhatia M, Walters MC. Hematopoietic cell transplantation for thalassemia and sickle cell disease: past, present and future. Bone Marrow Transplant 2008; 41(2):109-117.

9. Hacein-Bey-Abina S, Von Kalle C, Schmidt M, McCormack MP, Wulffraat $\mathrm{N}$, Leboulch $\mathrm{P}$, et al. LMO2-associated clonal $\mathrm{T}$ cell proliferation in two patients after gene therapy for SCID-X1. Science. 2003; 302(5644):415-419.

10. Gaspar HB, Parsley KL, Howe S, King D, Gilmour KC, Sinclair J, et al. Gene therapy of X-linked severe combined immunodeficiency by use of a pseudotyped gammaretroviral vector. Lancet. 2004; 364(9452):2181-2187.

11. Ott MG, Schmidt M, Schwarzwaelder K, Stein S, Siler U, Koehl U, et al. Correction of X-linked chronic granulomatous disease by gene therapy, augmented by insertional activation of MDS1-EVI1, PRDM16 or SETBP1. Nat Med. 2006; 12(4):401-409.

12. Hacein-Bey-Abina S, Garrigue A, Wang GP, Soulier J, Lim A, Morillon E et al. Insertional oncogenesis in 4 patients after retrovirus-mediated gene therapy of SCID-X1. J Clin Invest. 2008; 118(9):3132-3142.

13. Aiuti A, Cattaneo F, Galimberti S, Benninghoff U, Cassani B, Callegaro $\mathrm{L}$, et al. Gene Therapy for Immunodeficiency Due to Adenosine Deaminase Deficiency. New Engl J Med. 2009; 360(5):447-458.

14. Neff T, Beard BC, Kiem HP. Survival of the fittest: in vivo selection and stem cell gene therapy. Blood 2006, 107(5):1751-1760.

15. Miccio A, Cesari R, Lotti F, Rossi C, Sanvito F, Ponzoni M, et al. In vivo selection of genetically modified erythroblastic progenitors leads to long-term correction of beta-thalassemia. Proc Natl Acad Sci U S A 2008, 105(30):10547-10552.

16. Gaziev J, Lucarelli G. Stem cell transplantation for hemoglobinopathies Curr Opin Pediatr. 2003; 15(1):24-31.

17. Persons DA, Allay ER, Sabatino DE, Kelly P, Bodine DM, Nienhuis AW.
Functional requirements for phenotypic correction of murine betathalassemia: implications for human gene therapy. Blood. 2001; 97(10):3275-3282.

18. Rivella S, May C, Chadburn A, Riviere I, Sadelain M. A novel murine model of Cooley anemia and its rescue by lentiviral-mediated human beta-globin gene transfer. Blood. 2003; 101(8):2932-2939.

19. Li Q, Zhang M, Duan Z, Stamatoyannopoulos G. Structural analysis and mapping of DNase I hypersensitivity of HS5 of the beta-globin locus control region. Genomics. 1999; 61(2):183-193.

20. Ney PA, Sorrentino BP, McDonagh KT, Nienhuis AW. Tandem AP-1binding sites within the human beta-globin dominant control region function as an inducible enhancer in erythroid cells. Genes Dev. 1990; 4(6):993-1006

21. Milot E, Strouboulis J, Trimborn T, Wijgerde M, de Boer E, Langeveld A, et al. Heterochromatin effects on the frequency and duration of LCRmediated gene transcription. Cell. 1996; 87(1):105-114.

22. Dzierzak EA, Papayannopoulou T, Mulligan RC. Lineage-specific expression of a human beta-globin gene in murine bone marrow transplant recipients reconstituted with retrovirus-transduced stem cells. Nature. 1988; 331(6151):35-41.

23. van Beusechem VW, Kukler A, Heidt PJ, Valerio D. Long-term expression of human adenosine deaminase in rhesus monkeys transplanted with retrovirus-infected bone-marrow cells. Proc Natl Acad Sci U S A. 1992; 89(16):7640-7644.

24. Dunbar CE, Cottler-Fox M, O’Shaughnessy JA, Doren S, Carter C, Berenson R, et al. Retrovirally marked CD34-enriched peripheral blood and bone marrow cells contribute to long-term engraftment after autologous transplantation. Blood. 1995; 85(11):3048-3057.

25. Montini E, Cesana D, Schmidt M, Sanvito F, Bartholomae CC, Ranzani $\mathrm{M}$, et al. The genotoxic potential of retroviral vectors is strongly modulated by vector design and integration site selection in a mouse model of HSC gene therapy. J Clin Invest. 2009; 119(4):964-975.

26. Maruggi G, Porcellini S, Facchini G, Perna SK, Cattoglio C, Sartori D, et al. Transcriptional enhancers induce insertional gene deregulation independently from the vector type and design. Mol Ther. 2009; 17(5):851-856.

27. Modlich U, Bohne J, Schmidt M, von Kalle C, Knoss S, Schambach A, et al. Cell-culture assays reveal the importance of retroviral vector design for insertional genotoxicity. Blood. 2006; 108(8):2545-2553.

28. Challita PM, Kohn DB. Lack of expression from a retroviral vector after transduction of murine hematopoietic stem cells is associated with methylation in vivo. Proc Natl Acad Sci U S A. 1994; 91(7):2567-2571.

29. Perumbeti A, Higashimoto T, Urbinati F, Franco R, Meiselman HJ, Witte $\mathrm{D}$, et al. A novel human gamma-globin gene vector for genetic correction of sickle cell anemia in a humanized sickle mouse model: critical determinants for successful correction. Blood. 2009; 114(6):1174-1185.

30. Li CL, Xiong D, Stamatoyannopoulos G, Emery DW. Genomic and functional assays demonstrate reduced gammaretroviral vector genotoxicity associated with use of the cHS4 chromatin insulator. Mol Ther. $2009 ; 17(4): 716-724$.

31. Stathopulos PB. Taking the good out of the bad: lentiviral-based gene therapy of the hemoglobinopathies. Biotechnol Adv. 2003; 21(6):513526.

32. Imren S, Fabry ME, Westerman KA, Pawliuk R, Tang P, Rosten PM, et al. High-level beta-globin expression and preferred intragenic integration after lentiviral transduction of human cord blood stem cells. J Clin Invest. 2004; 114(7):953-962.

33. Hargrove PW, Kepes S, Hanawa H, Obenauer JC, Pei D, Cheng C, et al. Globin lentiviral vector insertions can perturb the expression of endogenous genes in beta-thalassemic hematopoietic cells. Mol Ther. 2008; 16(3):525-533. 
34. Arumugam PI, Higashimoto T, Urbinati F, Modlich U, Nestheide $\mathrm{S}$, Xia P, et al. Genotoxic potential of lineage-specific lentivirus vectors carrying the beta-globin locus control region. Mol Ther. 2009; 17(11):1929-1937.

35. Ramezani A, Hawley TS, Hawley RG. Combinatorial incorporation of enhancer-blocking components of the chicken beta-globin 5'HS4 and human T-cell receptor alpha/delta BEAD-1 insulators in selfinactivating retroviral vectors reduces their genotoxic potential. Stem Cells. 2008; 26(12):3257-3266.

36. May C, Rivella S, Chadburn A, Sadelain M. Successful treatment of murine beta-thalassemia intermedia by transfer of the human betaglobin gene. Blood. 2002; 99(6):1902-1908.

37. Puthenveetil G, Scholes J, Carbonell D, Qureshi N, Xia P, Zeng L, et al. Successful correction of the human beta-thalassemia major phenotype using a lentiviral vector. Blood. 2004; 104(12):3445-3453.

38. Pawliuk R, Westerman KA, Fabry ME, Payen E, Tighe R, Bouhassira EE, et al. Correction of sickle cell disease in transgenic mouse models by gene therapy. Science. 2001; 294(5550):2368-2371.

39. Levasseur DN, Ryan TM, Pawlik KM, Townes TM. Correction of mouse model of sickle cell disease: lentiviral/antisickling beta-globin gene transduction of unmobilized, purified hematopoietic stem cells. Blood. 2003; 102(13):4312-4319.

40. Romero Z, Urbinati F, Geiger S, Cooper AR, Wherley J, Kaufman ML et al. beta-globin gene transfer to human bone marrow for sickle cell disease. J Clin Invest. 2013.

41. Persons DA, Hargrove PW, Allay ER, Hanawa H, Nienhuis AW. The degree of phenotypic correction of murine beta -thalassemia intermedia following lentiviral-mediated transfer of a human gammaglobin gene is influenced by chromosomal position effects and vector copy number. Blood. 2003; 101(6):2175-2183.

42. Pestina TI, Hargrove PW, Jay D, Gray JT, Boyd KM, Persons DA Correction of murine sickle cell disease using gamma-globin lentiviral vectors to mediate high-level expression of fetal hemoglobin. Mol Ther. 2009; 17(2):245-252.

43. Perumbeti A, Malik P. Genetic correction of sickle cell anemia and beta-thalassemia: progress and new perspective. Scientific World Journal. 2010; 10:644-654.

44. Cavazzana-Calvo M, Payen E, Negre O, Wang G, Hehir K, Fusil F, et al. Transfusion independence and HMGA2 activation after gene therapy of human beta-thalassaemia. Nature. 2010; 467(7313):318-322.

45. Kanter J WM, Hsieh M, Thompson AA, Krishnamurti L, Kwiatkowski $\mathrm{H}$, et al. Initial results from study Hgb-206: a phase 1 study evaluating gene therapy by transplantation of autologous CD34+ stem cells transduced ex vivo with the lentiglobin BB305 lentiviral vector in subjects with severe sickle cell disease In: 57th American Society of Hematology Meeting. Orlando, Florida. 2015.

46. Cavazzana-Calvo M. In: 57th American Society of Hematology Meeting Orlando, Florida. 2015.

47. In: 57th American Society of Hematology Meeting. Orlando, Florida. 2015.

48. In: Tenth Cooley's Anemia Symposium Meeting. Chicago, Illinois. 2015.

49. Finotti A, Breda L, Lederer CW, Bianchi N, Zuccato C, Kleanthous M, et al. Recent trends in the gene therapy of beta-thalassemia. J Blood Med. 2015; 6:69-85.

50. Jinek M, Chylinski K, Fonfara I, Hauer M, Doudna JA, Charpentier E. A programmable dual-RNA-guided DNA endonuclease in adaptive bacterial immunity. Science. 2012; 337(6096):816-821.

51. Sakuma T, Nishikawa A, Kume S, Chayama K, Yamamoto T. Multiplex genome engineering in human cells using all-in-one CRISPR/Cas9 vector system. Sci Rep. 2014; 4:5400.

52. Chapman JR, Taylor MR, Boulton SJ. Playing the end game: DNA doublestrand break repair pathway choice. Mol Cell. 2012; 47(4):497-510.

53. Chen F, Pruett-Miller SM, Huang Y, Gjoka M, Duda K, Taunton J, et al. High-frequency genome editing using ssDNA oligonucleotides with zinc-finger nucleases. Nat Methods. 2011; 8(9):753-755.

54. Hirsch ML, Green L, Porteus MH, Samulski RJ. Self-complementary AAV mediates gene targeting and enhances endonuclease delivery for double-strand break repair. Gene Ther. 2010; 17(9):1175-1180.

55. Deng W, Rupon JW, Krivega I, Breda L, Motta I, Jahn KS, et al. Reactivation of developmentally silenced globin genes by forced chromatin looping. Cell. 2014; 158(4):849-860.

56. Vierstra J, Reik A, Chang KH, Stehling-Sun S, Zhou Y, Hinkley SJ, Paschon DE, et al. Functional footprinting of regulatory DNA. Nat Methods. 2015; 12(10):927-930.

57. Sun N, Zhao H. Seamless correction of the sickle cell disease mutation of the HBB gene in human induced pluripotent stem cells using TALENs. Biotechnol Bioeng. 2014; 111(5):1048-1053.

58. Chang CJ, Bouhassira EE. Zinc-finger nuclease-mediated correction of alpha-thalassemia in iPS cells. Blood. 2012; 120(19):3906-3914.

59. Samakoglu S, Lisowski L, Budak-Alpdogan T, Usachenko Y, Acuto $\mathrm{S}$, Di Marzo R, et al. A genetic strategy to treat sickle cell anemia by coregulating globin transgene expression and RNA interference. Nat Biotechnol. 2006; 24(1):89-94.

60. Zuccato C, Breda L, Salvatori F, Breveglieri G, Gardenghi S, Bianchi N, et al. A combined approach for beta-thalassemia based on gene therapymediated adult hemoglobin ( $\mathrm{HbA})$ production and fetal hemoglobin (HbF) induction. Ann Hematol. 2012; 91(8):1201-1213.

61. Bauer DE, Kamran SC, Lessard S, Xu J, Fujiwara Y, Lin C, et al. An erythroid enhancer of BCL11A subject to genetic variation determines fetal hemoglobin level. Science. 2013; 342(6155):253-257.

62. Canver MC, Smith EC, Sher F, Pinello L, Sanjana NE, Shalem O, et al. BCL11A enhancer dissection by Cas9-mediated in situ saturating mutagenesis. Nature. 2015; 527(7577):192-197.

63. Hoban MD, Cost GJ, Mendel MC, Romero Z, Kaufman ML, Joglekar $\mathrm{AV}$, et al. Correction of the sickle cell disease mutation in human hematopoietic stem/progenitor cells. Blood. 2015, 125(17):25972604.

64. Sebastiano V, Maeder ML, Angstman JF, Haddad B, Khayter C, Yeo DT et al. In situ genetic correction of the sickle cell anemia mutation in human induced pluripotent stem cells using engineered zinc finger nucleases. Stem Cells. 2011; 29(11):1717-1726.

65. Xie F, Ye L, Chang JC, Beyer AI, Wang J, Muench MO, et al. Seamless gene correction of beta-thalassemia mutations in patient-specific iPSCs using CRISPR/Cas9 and piggyBac. Genome Res. 2014; 24(9):15261533.

66. Huang X, Wang Y, Yan W, Smith C, Ye Z, Wang J, et al. Production of Gene-Corrected Adult Beta Globin Protein in Human Erythrocytes Differentiated from Patient iPSCs After Genome Editing of the Sickle Point Mutation. Stem Cells. 2015; 33(5):1470-1479.

67. Jang J, Quan Z, Yum YJ, Song HS, Paek S, Kang HC. Induced pluripotent stem cells for modeling of pediatric neurological disorders. Biotechnol J. 2014; 9(7):871-881.

68. Veres A, Gosis BS, Ding Q Collins R, Ragavendran A, Brand H, et al Low incidence of off-target mutations in individual CRISPR-Cas9 and TALEN targeted human stem cell clones detected by whole-genome sequencing. Cell Stem Cell. 2014; 15(1):27-30.

69. Ma N, Shan Y, Liao B, Kong G, Wang C, Huang K, et al. Factor-induced Reprogramming and Zinc Finger Nuclease-aided Gene Targeting 
Cause Different Genome Instability in beta-Thalassemia Induced Pluripotent Stem Cells (iPSCs). J Biol Chem. 2015; 290(19):1207912089.

70. Vo LT, Daley GQ. De novo generation of HSCs from somatic and pluripotent stem cell sources. Blood. 2015; 125(17):2641-2648.
71. Vanhee S, Vandekerckhove B. Pluripotent stem cell based gene therapy for hematological diseases. Crit Rev Oncol Hematol. 2016; 97:238-246.

72. Cohen AR, Glimm E, Porter JB. Effect of transfusional iron intake on response to chelation therapy in beta-thalassemia major. Blood. 2008; 111(2):583-587. 